\section{A woman with sudden-onset facial oedema}

An 84-year-old woman presented with acute facial oedema that developed suddenly $2 \mathrm{~h}$ prior to the visit. She had no particular medical history, no episode of neck injury, nor was she on any anticoagulant or antiplatelet agent. CT showed a pharyngeal mass (figure 1), which was confirmed as a retropharyngeal haematoma with a nasopharyngeal fiberscope (figure 2). A clinical diagnosis of spontaneous retropharyngeal haematoma was established.

Retropharyngeal haematoma is a rare but potentially lifethreatening condition; it can progress rapidly, causing airway obstruction once it starts to grow. ${ }^{1}$ It has been reported to develop in patients who have suffered blunt head or neck trauma or who are on anticoagulants or antiplatelet agents, and spontaneous cases are rare.

Airway management is crucial; prophylactic intubation or tracheostomy is sometimes considered. For this patient, given that the retropharyngeal haematoma was too small to perform tracheal intubation even when it enlarged, we followed the haematoma with a nasopharyngeal fiberscope every $30 \mathrm{~min}$ after diagnosis. No growth of the haematoma was confirmed after the first examination. The haematoma started to resolve on the third day, and the facial oedema disappeared accordingly, resulting in complete recovery.

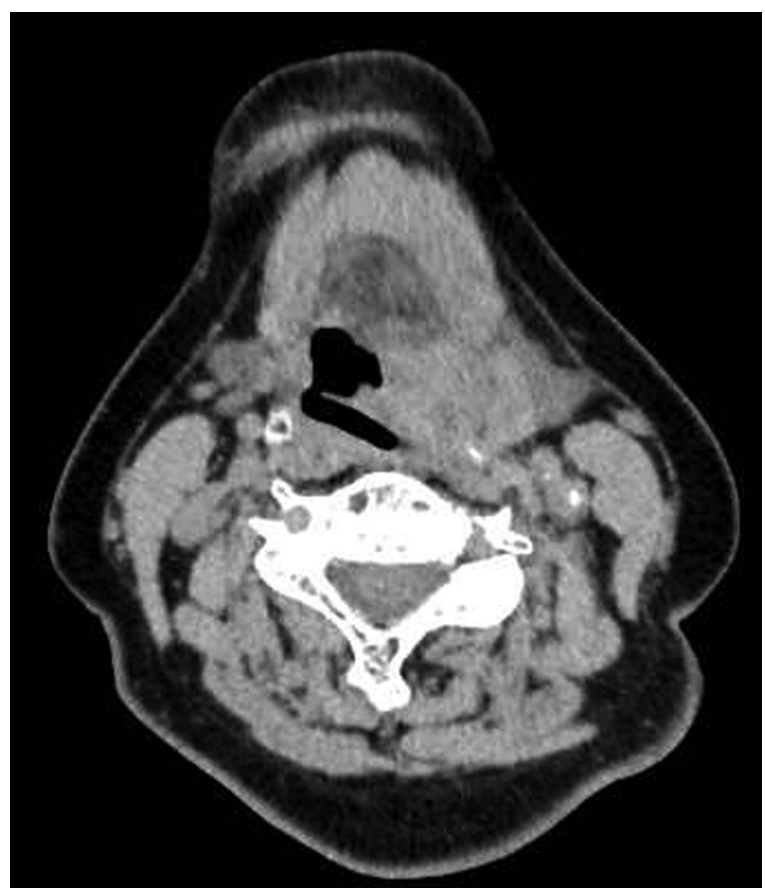

Figure $1 \mathrm{CT}$.

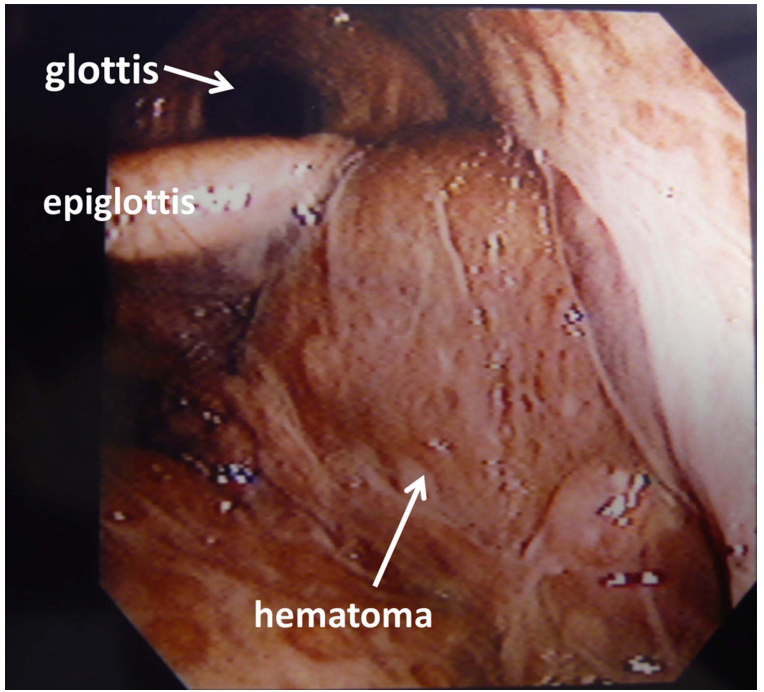

Figure 2 Clinical diagnosis of spontaneous retropharyngeal haematoma.

\section{Takashi Fujiwara, ${ }^{1}$ Akira Kuriyama, ${ }^{2}$ Taro Shimizu ${ }^{3}$}

${ }^{1}$ Department of Otolaryngology Head and Neck Surgery, Ehime University, Ehime, Japan

${ }^{2}$ Department of General Medicine, Kurashiki Central Hospital, Okayama, Japan

${ }^{3}$ Department of General Internal Medicine, Hikarigaoka Hospital, Tokyo, Japan

Correspondence to Takashi Fujiwara, Department of Otolaryngology Head and Neck Surgery, Ehime University School of Medicine, ShitsukawaToon City, Ehime 791-0295, Japan; t.fujiwarabi@gmail.com

Contributors TF and AK looked after the patient, and wrote the draft. All authors approved the submission of the current manuscript.

Competing interests None.

Patient consent Obtained.

Ethics approval Kurashiki Central Hospital.

Provenance and peer review Not commissioned; internally peer reviewed.

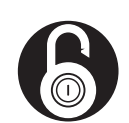
OPEN ACCESS

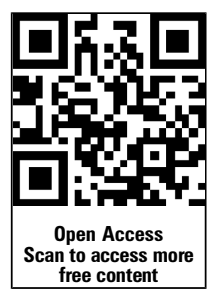

Open Access This is an Open Access article distributed in accordance with the Creative Commons Attribution Non Commercial (CC BY-NC 3.0) license, which permits others to distribute, remix, adapt, build upon this work non-commercially, and license their derivative works on different terms, provided the original work is properly cited and the use is non-commercial. See: http://creativecommons.org/ licenses/by-nc/3.0/

Received 26 December 2012

Accepted 7 January 2013

Published Online First 30 January 2013

Emerg Med J 2013;30:985. doi:10.1136/emermed-2012-202314

\section{REFERENCE}

1. Bloom DC, Haegen T, Keefe MA. Anticoagulation and spontaneous retropharyngeal hematoma. J Emerg Med 2003;24:389-94. 